\title{
Efeitos de regulador de crescimento, controle de doenças e densidade de semeadura na qualidade industrial de grãos de arroz
}

\author{
Effects of the growth regulator, disease control and sowing density on the industrial quality of rice grains
}

\author{
Valdinei Sofiatti ${ }^{1}$ Luis Osmar Braga Schuch ${ }^{2}$ Jonas Farias Pinto $^{3}$ Adeliano Cargnin ${ }^{3}$ Luciane Nolasko \\ Leitzke $^{3}$ Letícia Dos Santos Hölbig ${ }^{3}$
}

\section{RESUMO}

O objetivo foi avaliar o efeito da aplicação do regulador de crescimento ethephon visando à uniformidade de floração e maturação e o controle de doenças de final de ciclo da cultura do arroz. Foi utilizado o fungicida tebuconazole e a avaliou-se a qualidade industrial de grãos das cultivares IRGA 417 e El Paso L 144, em duas densidades de semeadura. $O$ experimento consistiu de uma combinação fatorial $(2 \times 2 \times 4)$ de duas cultivares (IRGA 417 e El Paso L 144), duas densidades de semeadura (50 e $\left.150 \mathrm{~kg} \mathrm{ha}^{-1}\right)$, e quatro tratamentos foliares (1-testemunha, 2-ethephon, 3-fungicida, 4-ethephon + fungicida), em um delineamento experimental de blocos ao acaso com três repetições. Foi avaliado o percentual de grãos inteiros, e de grãos com gessamento parcial. O percentual de grãos inteiros foi similar em todos os tratamentos, exceto para o tratamento químico com ethephon + fungicida na cultivar IRGA 417, que apresentou menor percentagem de grãos inteiros. Para a percentagem de grãos com gessamento parcial, houve interação entre cultivares, densidades de semeadura e tratamentos foliares. A incidência de gessamento foi maior na cultivar El Paso L 144, porém, nesta cultivar, a pulverização de ethephon na densidade de semeadura de $150 \mathrm{~kg} \mathrm{ha}^{-1}$, proporcionou redução considerável do percentual de grãos com gessamento.

Palavras-chave: uniformidade de florescimento, gessamento parcial, ethephon, grãos inteiros.

\section{ABSTRACT}

This study was carried out to evaluate the application effects of the growth regulator ethephon on the flowering and maturation uniformity and disease control at the end of the crop cycle. The effect of the fungicide tebuconazole,

\begin{abstract}
on the grain quality of the cultivars IRGA 417 and El Paso L 144 was evaluated in two sowing densities. The experiment consisted of a factorial combination $(2 \times 2 \times 4)$ of two cultivars (IRGA 417 and El Paso L 144), two sowing densities (50 and 150kg ha-1) and four leaf treatments (1-no chemical treatment, 2-ethephon, 3-fungicide, 4-ethephon + fungicide). The experimental design was a randomized complete block with three replicates. Percentage of whole grains and partially plastered grains were determined. The percentage of the whole grains was similar in all treatments, except for the application of ethephon + fungicide in the cultivar IRGA 417, and showed the lowest percentage of whole grains. There are interaction among the cultivars, sowing densities, and leaf treatments for the percentage of partially plastered grains. Plastering occurrence was higher in El Paso L 144, although the application of ethephon at the sowing density of $150 \mathrm{~kg} \mathrm{ha}^{-1}$ provided high reduction in the plastered grain percentage.
\end{abstract}

Key words: florescence uniformity, partial plastering, ethephon, whole grains.

\section{INTRODUÇÃO}

O preço do grão de arroz pago ao agricultor depende fundamentalmente da qualidade, verificada após o beneficiamento, sendo que o percentual de grãos inteiros é uma das características mais importantes para determinar o valor de comercialização (MARCHEZAN et al., 1993). Além do percentual de inteiros, outro aspecto importante relacionado com a qualidade do grão de arroz é referente a translucidez.

\footnotetext{
${ }^{1}$ Departamento de Fitotecnia, Universidade Federal de Viçosa (UFV). Getúlio Vargas 169, Bairro Bom Jesus, 36570-000, Viçosa, MG, Brasil. E-mail: sufiatti@vicosa.ufv.br. Autor para correspondência.

${ }^{2}$ Departamento de Fitotecnia, Universidade Federal de Pelotas (UFPel). Caixa Postal 354, 96010-900, Pelotas, RS, Brasil. E-mail: lobs@ufpel.edu.br.

${ }^{3}$ Curso de Agronomia da UFPel. Pelotas, RS, Brasil.
} 
Em muitos grãos, a translucidez é interrompida por áreas opacas no endosperma denominadas centro branco, barriga branca ou gesso, as quais depreciam o valor do produto no mercado (SILVA \& BRANDÃO, 1987). De acordo com a portaria 269 do Ministério da Agricultura, Pecuária e Abastecimento a opacidade dos grãos é denominada gessamento e são considerados gessados os grãos com $100 \%$ do endosperma opaco. No entanto, mesmo os grãos com pequenas áreas gessadas depreciam o valor comercial do produto.

O gessamento é causado por espaços aéreos entre os grânulos de amido (GALLI, 1978; JENNINGS et al., 1981; SRINIVAS \& BHASHYAM, 1985), ou por um acondicionamento mais frouxo entre os grânulos de amido e proteína (NANGJU \& DE DATTA, 1970; VIEIRA \& CARVALHO, 1999). Entre as possíveis causas da formação dessas áreas opacas estariam as de origem genética (JENNINGS et al., 1981), à condições ambientais adversas (MARTINEZ \& CUEVAS, 1989), a má formação dos grãos pela incidência de doenças (SOAVE et al., 1988), e grande quantidade de grãos imaturos, ou alto grau de umidade e ataque de insetos sugadores antes da colheita (VIEIRA \& CARVALHO, 1999).

A desuniformidade de maturação ocasiona variação no teor de água entre os grãos que compõem a amostra no momento da colheita e conduz a formação de áreas esbranquiçadas que conseqüentemente causam a quebra dos grãos, aumentando a quantidade desses defeitos à medida que a amplitude no teor de água dos mesmos aumenta (MARCHEZAN et al., 1993). A origem dessa diferença está relacionada a vários fatores, dentre os quais se destaca a floração das espiguetas dentro de uma mesma panícula não ocorrer de maneira uniforme, iniciando nas ramificações superiores deslocando-se para a base da panícula (NEDEL et al., 1998), o afilhamento e a duração do período de floração da cultivar (MARCHEZAN, 1991), a uniformidade de emergência e a densidade de semeadura(RODRIGUES, 2001).

A planta de arroz apresenta grande amplitude de umidade entre os grãos da base para o ápice da panícula, podendo essa diferença ser superior a $10 \%$ de umidade em algumas cultivares, sendo que cultivares que apresentam rendimento de engenho superior possuem a menor amplitude de umidade dos grãos dentro da mesma panícula (MARCHEZAN, 1991). Resultados semelhantes quanto à variação no grau de umidade também são relatados por CHAU \& KUNZE (1982).

Atualmente têm-se utilizado a pulverização das plantas com reguladores de crescimento, como o ácido 2-cloro ethil fosfônico (ethephon) para acelerar e uniformizar o florescimento e conseqüentemente a maturação dos frutos de diversas espécies vegetais (ARTECA, 1996). Em arroz, a informação sobre a ação desse regulador de crescimento é escassa (CARBONE \& VIDAL, 1997). Embora o ethephon esteja registrado no Ministério da Agricultura, Pecuária e Abastecimento para uso na cultura do arroz, há carência de trabalhos científicos sobre a ação na planta. Quando aplicado sobre as plantas de arroz, este composto proporciona a liberação de etileno interferindo nos processos fisiológicos dos tecidos vegetais (BARROS, 1991). O etileno é um hormônio que regula diversos processos fisiológicos da planta, entre eles a senescência das folhas nos cereais (CARBONE \& VIDAL, 1997).

A incidência de doenças fúngicas também afetam a qualidade industrial dos grãos de arroz. Alguns fungos podem afetar a planta de arroz, causando produção de grãos manchados, chochos, de menor peso ou com lesões necróticas (NAKAMURA \& SADER, 1986). Fungos secundários também estão relacionados a manchas de grãos e aumentam a incidência de grãos gessados, afetando o rendimento industrial (SOAVE et al., 1988).

O objetivo foi avaliar o efeito da aplicação do regulador de crescimento ethephon visando a uniformidade de floração e maturação e o controle de doenças de final de ciclo da cultura pela utilização do fungicida tebuconazole, sobre a qualidade industrial dos grãos das cultivares IRGA 417 e El Paso L 144, em duas densidades de semeadura.

\section{MATERIAL E MÉTODOS}

O experimento foi conduzido na área experimental do Centro Agropecuário da Palma, pertencente à Faculdade de Agronomia Eliseu Maciel da Universidade Federal de Pelotas (CAP/UFPel), localizado no município de Capão do Leão - RS, situado na Encosta do Sudoeste do Estado do Rio Grande do Sul, a $31^{\circ} 52^{\prime}$ de latitude sul e $52^{\circ} 21^{\prime}$ 'de longitude oeste de Greenwich.

O solo é classificado como Planossolo (hidromórfico) e pertence à unidade de mapeamento Pelotas. A adubação de base foi feita com $10 \mathrm{~kg} \mathrm{ha}^{-1}$ de $\mathrm{N}, 40 \mathrm{~kg} \mathrm{ha}^{-1}$ de $\mathrm{P}_{2} \mathrm{O}_{5}$ e $40 \mathrm{~kg} \mathrm{ha}^{-1}$ de $\mathrm{K}_{2} \mathrm{O}$, nas formas de uréia, superfosfato triplo e cloreto de potássio, respectivamente, de acordo com as recomendações da COMISSÃO DE FERTILIDADE DO SOLO - RS/SC (1995). Na adubação de cobertura, foram utilizados $90 \mathrm{~kg}$ $\mathrm{ha}^{-1}$ de $\mathrm{N}$ na forma de uréia a qual foi aplicada em duas frações iguais nos estádios de afilhamento (25 dias após a semeadura) e início da diferenciação da panícula (IDP). A semeadura foi realizada em 17 de dezembro de 
2002 utilizando-se uma semeadora-adubadeira de parcelas, sendo o controle de plantas daninhas efetuado através da aplicação de 360 gramas de ingrediente ativo por hectare (g i.a. ha-1) do herbicida cyhalofop-butyl aos 20 dias após a semeadura, com início da irrigação por inundação dois dias após a aplicação do produto.

O experimento consistiu de uma combinação fatorial (2x2x4) de duas cultivares, duas densidades de semeadura, e quatro tratamentos foliares aplicados na parte aérea das plantas durante o ciclo vegetativo da cultura, no delineamento experimental de blocos ao acaso com três repetições. Cada unidade experimental consistiu de nove linhas de $4 \mathrm{~m}$ de comprimento, espaçadas $0,17 \mathrm{~m}$ entre si, sendo considerada como área útil as cinco linhas centrais da parcela. A densidade de semeadura foi corrigida para 50 e $150 \mathrm{~kg} \mathrm{ha}^{-1}$ de sementes viáveis. Foram utilizadas as cultivares IRGA 417 e El Paso L 144. Os tratamentos foliares foram: 1) ethephon, visando uniformizar o florescimento e maturação, 2) o fungicida tebuconazole, para o controle das doenças secundárias da cultura, 3) aplicação de ethephon e fungicida, e 4) testemunha sem tratamento químico. A aplicação de ethephon foi realizada quando as plantas atingiram o estádio de início de diferenciação da panícula (IDP), na dose de $360 \mathrm{~g}$ i.a. ha-1 . O fungicida foi aplicado na dose de $110 \mathrm{~g}$ i.a. ha- ${ }^{-1}$ por aplicação, sendo aplicado em três épocas: 1 -início do período de floração; 2- 50\% das panículas emitidas e 3-floração completa. Nas aplicações foi utilizado pulverizador costal pressurizado com $\mathrm{CO}_{2}$, utilizando água como veículo no volume de 200L ha ${ }^{-1}$. No tratamento testemunha não foi aplicado água.

Após a emergência, fez-se marcação de dois metros lineares no centro de cada parcela. Nessa área, foi realizada a contagem do número de plantas emergidas aos 15 dias após a semeadura (DAS). A cada dois dias, foram contadas as panículas emitidas para a determinação da uniformidade de emissão das mesmas. A determinação da uniformidade de emissão das panículas foi avaliada pelo desvio padrão, o qual foi determinado através da distribuição de freqüência do número de panículas emitidas por dia, após o início da emissão das primeiras panículas em cada parcela. Quanto maior o desvio padrão maior a desuniformidade na emissão das panículas.

A avaliação da incidência de doenças nas plantas foi realizada aproximadamente sete dias após a última aplicação de fungicida. Foram atribuídas notas de zero a nove para cada parcela conforme escala adaptada do CIAT (1980), onde a nota 0 corresponde à ausência de sintomas e nota 9 corresponde a 100\% da área foliar infectada por doenças.
Após a colheita, os grãos foram secados em silo secador estacionário com temperatura do ar de secagem de $38^{\circ} \mathrm{C}$ até atingirem $13 \%$ de umidade. Para a determinação do rendimento de grãos inteiros, as amostras foram pré-limpas e submetidas às operações de descascamento e brunimento em engenho de provas marca SUZUKI utilizando frações de 100 gramas de arroz em casca nas operações de engenho para cada amostra, com um tempo de descascamento e polimento de aproximadamente 1 minuto e 30 segundos em cada operação. Após essas etapas, fez-se a separação manual dos grãos inteiros com gessamento. Foram considerados grãos com gessamento parcial os que apresentavam qualquer parte do endosperma opaco e os resultados foram expressos em percentagem de grãos inteiros com gessamento parcial.

Os dados experimentais incluindo os desvios padrões obtidos de cada unidade experimental para a variável uniformidade de emissão das panículas foram submetidos à análise de variância, e os efeitos de tratamentos e interações avaliados pelo teste $\mathrm{F}$. $\mathrm{Na}$ ocorrência de interação entre dois ou mais fatores foi feita a comparação das médias dos níveis de um fator dentro dos níveis dos outros fatores envolvidos na interação através do teste de Duncan.

\section{RESULTADOS E DISCUSSÃO}

O número de plantas emergidas foi de 123 e 273 plantas por metro quadrado para as densidades de semeadura de 50 e $150 \mathrm{~kg}$ de sementes por hectare, respectivamente. A uniformidade de emissão das panículas, avaliada através da análise de variância do desvio padrão não apresentou diferenças significativas indicando não haver diferenças entre os tratamentos (dados não apresentados). Assim, mesmo na densidade de semeadura mais baixa na qual a planta emitiu maior número de afilhos não houve maior desuniformidade na emissão das panículas. Os afilhos florescem na mesma seqüência de seu surgimento, porém, num menor período de tempo comparativamente ao colmo principal (SRINIVAS \& BHASHYAM, 1985). Esse fato pode explicar a emissão das panículas ocorrer de maneira semelhante tanto em semeadura com densidade maior como em menor densidade.

A cultivar El Paso L 144 apresentou incidência de doenças mais elevada na ausência da aplicação de fungicida, mostrando maior susceptibilidade desta cultivar a doenças (Tabela 1). A aplicação de fungicida reduziu acentuadamente a incidência de doenças fúngicas em ambas as cultivares. A pulverização com fungicida reduziu a incidência de doenças da cultivar susceptível para níveis 
Efeitos de regulador de crescimento, controle de doenças e densidade de semeadura...

Tabela 1 - Incidência de doenças no campo (ID), percentual de grãos inteiros (PGI) e umidade média de colheita (UMC) nas cultivares El Paso L 144 (EP) e IRGA 417 (IRGA) submetidos a diferentes tratamentos foliares

\begin{tabular}{|c|c|c|c|c|c|}
\hline \multirow{2}{*}{$\begin{array}{l}\text { Tratamentos } \\
\text { foliares }\end{array}$} & \multicolumn{2}{|c|}{ ID (notas) } & \multicolumn{2}{|c|}{ PGI (\%) } & \multirow{2}{*}{ UMC (\%) } \\
\hline & EP & IRGA & EP & IRGA & \\
\hline Fungicida (F) & $0,7 c^{*}$ & $0,5 b$ & $65 a$ & $66 a$ & $28,2 \mathrm{a}$ \\
\hline Testemunha & $3,7 a$ & $1,4 a$ & $65 a$ & $64 a$ & $25,6 b$ \\
\hline Ethephon (E) & $2,3 b$ & 1,2ab & $67 a$ & $66 a$ & $25,7 b$ \\
\hline$E+F$ & $0,7 \mathrm{c}$ & $0,4 \mathrm{~b}$ & $67 a$ & $60 \mathrm{~b}$ & $28,1 \mathrm{a}$ \\
\hline CV (\%) & \multicolumn{2}{|c|}{36,0} & \multicolumn{2}{|c|}{3,2} & 8,8 \\
\hline
\end{tabular}

*Médias seguidas pela mesma letra não diferem entre si pelo teste de Duncan a 5\% de probabilidade de erro.

semelhantes aos da cultivar IRGA 417, superando dessa forma as diferenças de susceptibilidade entre as cultivares. A aplicação de ethephon também provocou redução na incidência de doenças em ambas as cultivares, embora de forma menos acentuada (Tabela 1).

A aplicação de fungicida ocasionou aumento na umidade de colheita dos grãos em torno de três pontos percentuais em relação aos tratamentos sem fungicidas (Tabela 1). Esse fato ocorreu, provavelmente, devido à baixa ocorrência de patógenos nas unidades experimentais pulverizadas com fungicidas, fazendo com que as plantas retardassem a senescência, permanecendo verdes por mais tempo. A análise de variância para a percentagem de grãos inteiros mostrou interação significativa entre cultivares e tratamentos foliares aplicados. A percentagem de grãos inteiros não apresentou variação em função dos tratamentos foliares na cultivar El Paso L 144, no entanto, na cultivar IRGA 417 o tratamento ethephon combinado com fungicida diferiu dos demais tratamentos apresentando menor percentual de grãos inteiros. A variação na densidade de semeadura não afetou o rendimento de grãos inteiros. Densidades de semeadura entre 100 e $300 \mathrm{~kg}$ ha $^{-1}$ de sementes não afetam o rendimento de grãos inteiros em arroz irrigado (CANELLAS et al., 1997).

A análise de variância do percentual de grãos inteiros com gessamento parcial apresentou interação entre cultivares, densidades de semeadura e tratamentos foliares. A cultivar IRGA 417 apresentou baixa percentagem de grãos com gessamento quando comparado com a cultivar El Paso L 144 (Tabela 2), devido às características genéticas dessa cultivar, não sendo afetada pela densidade de semeadura nem pelos tratamentos foliares. O caráter gessamento é governado por um gene com alelos recessivos (JENNINGS et al., 1981). No entanto, diversas formas de herança foram encontradas quando foi cruzado arroz cultivado com arroz vermelho ou preto, sugerindo a ocorrência de interações alélicas mais complexas (VALÉRIO, 1994).

Apesar desta característica ter origem genética, outros fatores ligados ao comportamento da planta sob diversas condições de manejo e de ambiente têm apresentado grande efeito sobre o caráter, principalmente em cultivares onde a ocorrência de grãos gessados é maior (JENNINGS et al., 1981). Na cultivar El Paso L 144, onde a ocorrência de gessamento foi maior, tanto a variação nos tratamentos foliares como na densidade de semeadura afetaram a percentagem de grãos com este defeito. Na densidade de semeadura de $150 \mathrm{~kg} \mathrm{ha}^{-1}$, a aplicação de ethephon reduziu a percentagem de grãos com gessamento parcial de 27,7\% no tratamento testemunha para 19,4\% (Tabela 2), porém, o mesmo não ocorreu na densidade de $50 \mathrm{~kg} \mathrm{ha}^{-1}$. Os tratamentos fungicida e ethephon combinado com fungicida apresentaram percentagem de gessamento parcial de 37,8 e 32,2\%, respectivamente, na densidade de $150 \mathrm{~kg} \mathrm{ha}^{-1}$ de sementes. Esses resultados são decorrentes da maior umidade dos grãos por ocasião da colheita, que ocorreu devido ao retardamento da senescência ocasionada pela aplicação de fungicida (Tabela 1). Grãos de arroz colhidos com umidade acima de 25,5\% apresentam aumento considerável na percentagem de gessamento (DIAS, 1991). Assim, a alta umidade dos grãos no momento da colheita é um dos principais fatores responsáveis pela ocorrência de gessamento (VIEIRA\& CARVALHO, 1999).

A diferença no grau de umidade entre os grãos que compõem a amostra, por ocasião da colheita, tem sido relatada como uma das mais prováveis causas do gessamento em cultivares susceptíveis a esse defeito. Isso se deve ao fato de que ao se realizar a determinação de umidade em uma amostra obtém-se a umidade média dos grãos, no entanto, dentro desta amostra, muitos dos grãos possuem umidades maiores e menores do que a média. Os grãos que apresentam umidades muito altas podem não estar totalmente

Ciência Rural, v.36, n.2, mar-abr, 2006. 
Tabela 2 - Efeito da aplicação de tratamentos foliares e da densidade de semeadura sobre a percentagem de grãos inteiros com gessamento parcial nas cultivares IRGA 417 e El Paso L 144.

\begin{tabular}{|c|c|c|c|c|}
\hline \multirow{2}{*}{ Tratamentos foliares } & \multicolumn{2}{|c|}{ IRGA 417} & \multicolumn{2}{|c|}{ El Paso L 144} \\
\hline & $50^{1}$ & 150 & 50 & 150 \\
\hline Testemunha & A $6,0 a^{2}$ & A $10,0 a$ & A $33,3 a b$ & A $27,7 b$ \\
\hline Ethephon + fungicida & A $5,7 a$ & A $6,1 \mathrm{a}$ & A $28,7 b$ & A 32,2ab \\
\hline Ethephon & A $8,4 a$ & A 5,0a & A $37,9 a$ & B $19,4 c$ \\
\hline Fungicida & A $6,5 a$ & A $10,0 a$ & A $38,0 a$ & A $37,8 a$ \\
\hline CV (\%) & \multicolumn{4}{|c|}{21,6} \\
\hline
\end{tabular}

${ }^{1}$ Densidade de semeadura em $\mathrm{kg} \mathrm{ha}^{-1}$.

${ }^{2}$ Médias seguidas pela mesma letra minúscula na coluna e maiúscula na linha dentro de uma mesma cultivar não diferem entre si pelo teste de Duncan a 5\% de probabilidade de erro.

formados ocasionando o gessamento (DIAS, 1991; VIEIRA\& CARVALHO, 1999).

A origem desta diferença no grau de umidade dos grãos está entre outros fatores relacionada ao afilhamento (MARCHEZAN, 1991), à emissão das panículas e à floração desuniforme das espiguetas dentro de uma mesma panícula. Na densidade de semeadura de $150 \mathrm{~kg} \mathrm{ha}^{-1}$ a aplicação de ethephon proporcionou redução de 8,3\% na percentagem de grãos com gessamento em relação à testemunha (Tabela 2). A aplicação deste regulador de crescimento não proporcionou maior uniformidade na emissão das panículas neste tratamento em relação aos demais. É possível, porém, que a aplicação de ethephon tenha uniformizado a floração das espiguetas dentro de uma mesma panícula e conseqüentemente proporcionado menor variação no grau de umidade entre os grãos neste tratamento. O tempo necessário para a floração de todas as espiguetas dentro de uma mesma panícula pode se estender de 5 a 10 dias (SRINIVAS \& BHASHYAM, 1985). Dessa forma, pode ocorrer grande variação no grau de umidade entre os grãos dentro de uma mesma panícula e conseqüentemente, a uniformização da floração das espiguetas dentro de uma mesma panícula, poderia reduzir consideravelmente a amplitude de umidade entre os grãos.

A aplicação de ethephon proporcionou menor incidência de gessamento parcial na cultivar El Paso L 144 somente na densidade de semeadura de $150 \mathrm{~kg} \mathrm{ha}^{-1}$. A variação no tamanho das panículas pode explicar parcialmente esses resultados. As panículas possuíam em média 52 grãos na densidade de $50 \mathrm{~kg} \mathrm{ha}^{-1}$ e 46 na densidade de $150 \mathrm{~kg} \mathrm{ha}^{-1}$. Dessa forma, a produção de panículas menores na densidade de semeadura mais alta pode ter contribuído para a redução da incidência de centro branco nesta densidade de semeadura. O menor tamanho da panícula contribui para a uniformidade de floração das espiguetas dentro da panícula, já que a floração nas espiguetas se inicia na extremidade superior da panícula e vai descendo até a base da mesma (NEDEL et al., 1998). Dessa maneira menor número de espiguetas ocasionaria menor espaço de tempo entre a floração das espiguetas superiores e inferiores.

A menor incidência de doenças foliares no campo (Tabela 1), proporcionada pela aplicação de fungicida, não ocasionou redução no percentual de grãos com gessamento. O maior grau de umidade dos grãos por ocasião da colheita nos tratamentos com pulverização de fungicida, possivelmente tenha sido a principal causa da alta incidência de gessamento nesses tratamentos. A aplicação de ethephon aliada à alta densidade de semeadura não uniformizou a emissão de panículas nas cultivares El Paso L 144 e IRGA 417. Entretanto, a aplicação de ethephon na densidade de semeadura de $150 \mathrm{~kg} \mathrm{ha}^{-1}$ proporcionou redução da incidência de gessamento parcial nos grãos da cultivar El Paso L 144. A cultivar El Paso L 144 apresentou maior percentagem de grãos com gessamento parcial do que a cultivar IRGA 417. A aplicação de fungicida ocasionou retardamento da senescência das plantas de arroz promovendo maior umidade dos grãos por ocasião da colheita.

\section{REFERÊNCIAS}

ARTECA, R.N. Plant growth substances: principles and applications. New York, 1996. 332p.

BARROS, J. de A.I. Efeitos de ethephon em três cultivares de arroz (Oryza sativa L.) irrigado. Lavoura Arrozeira, Porto Alegre, v.44, n.398, p.20-23, 1991.

Ciência Rural, v.36, n.2, mar-abr, 2006. 
CANELLAS, L.P. et al. Efeito de práticas de manejo sobre o rendimento de grãos e a qualidade industrial dos grãos em arroz irrigado. Ciência Rural, Santa Maria, v.27, n.3, p.375-379, 1997.

CARBONE A.; VIDAL, A. Evolución de la producción de etileno en la hoja bandera y la panoja de arroz (Oryza sativa L.) y sus efectos sobre la calidad del grano. Revista de la Facultad de Agronomía, La Plata, v.102, n.02, p.197-202, 1997.

CENTRO INTERNACIONAL DE AGRICULTURA TROPICAL - CIAT. Sistema de evaluación estándar para arroz. Calli: CIAT, 1980. 83p.

CHAU, N.N.; KUNZE, O.R. Moisture content variation among harvested rice grains. Transactions of the ASAE, St. Joseph, v.25, n.4, p.1037-1040, 1982.

COMISSÃO DE FERTILIDADE DO SOLO - RS/SC. Recomendações de adubação e calagem para os Estados do Rio Grande do Sul e Santa Catarina (ROLAS). 3.ed. Passo Fundo: SBCS - Núcleo Regional Sul/EMBRAPA-CNPT, 1995. 223p.

DIAS, A.R.G. Efeitos de cinco umidades de colheita e de beneficiamento no desempenho industrial de cinco variedades de arroz (Oryza sativa L.) irrigado. 1991. 85f. Dissertação (Mestrado em Ciência e Tecnologia Agroindustrial) Faculdade de Agronomia Eliseu Maciel, Universidade Federal de Pelotas.

GALLI, J. Sobre as causas do "GESSO” em arroz. Lavoura Arrozeira, Porto Alegre, v.31, n.309, p.22-26, 1978.

JENNINGS, P.R. et al. Mejoramento de arroz. Calli: CIAT, 1981. 237p.

MARCHEZAN, E. Relações entre época de semeadura, de colheita e rendimento industrial em grãos inteiros de cultivares de arroz (Oryza sativa L.). 1991. 102f. Tese (Doutorado em Agronomia) - Escola Superior de Agricultura Luiz de Queirós, Universidade de São Paulo.

MARCHEZAN, E. et al. Relações entre épocas de semeadura, de colheita e rendimento de inteiros de cultivares de arroz irrigado. Pesquisa Agropecuária Brasileira, Brasília, v.28, n.7, p.843-848, 1993.
MARTINEZ, C.; CUEVAS, F. Evaluación de la calidad culinária y molinera del arroz. Guía de estudio. Calli: CIAT, 1989. 75p.

NAKAMURA, A.M.; SADER, R. Efeito da infecção por fungos na germinação e vigor de sementes de arroz. Revista Brasileira de Sementes, Pelotas, v.8, n.1, p.101-111, 1986

NANGJU, D.; DE DATTA, S.K. Effect of time of harvest and nitrogen level on yield and grain breakage in transplanted rice. Agronomy Journal, Madison, v.62, p.468-474, 1970.

NEDEL, J.L. et al. A planta de arroz: morfologia e fisiologia. In: PESKE, S.T. et al. Produção de arroz. Pelotas: Universidade Federal de Pelotas, 1998. Cap.1, p.11-66.

RODRIGUES, A.O. Sementes verdes e qualidade de sementes de arroz (Oryza sativa L.). 2001. 24f. Dissertação (Mestrado em Ciência e Tecnologia de Sementes) - Faculdade de Agronomia Eliseu Maciel, Universidade Federal de Pelotas.

SILVA, P.S.L.; BRANDÃO, S.S. Rendimento no beneficiamento e translucidez de grãos de cultivares de arroz em função de níveis de nitrogênio. Pesquisa Agropecuária Brasileira, Brasília, v.22, p.943-949, 1987.

SOAVE, J. et al. Índice de intensidade de infecção adaptado ao estudo de manchas de sementes de arroz. Bragantia, Campinas, v.47, n.2, p.223-237, 1988

SRINIVAS, T.; BHASHYAM, M.K. Effect of variety environment of milling quality of rice. In: ______. Rice grain quality a marketing. Manila: IRRI, 1985 . p.49-59.

VALÉRIO, M. da G. B. Qualidade culinária do arroz (Oryza sativa L.) daninho e seu aproveitamento para o melhoramento genético do cultivado. 1994. $76 \mathrm{f}$. Dissertação (Mestrado em Agronomia) - Faculdade de Agronomia Eliseu Maciel, Universidade Federal de Pelotas.

VIEIRA, N.R. de A.; CARVALHO, J.L.V. de. Qualidade tecnológica. In: VIEIRA, N.R. et al. A cultura do arroz no Brasil. Goiânia: EMBRAPA Arroz e Feijão, 1999. Cap.21, p.582-604. 